ARTICLE OPEN

\title{
The impact of on-premises piped water supply on fecal contamination pathways in rural Zambia
}

\author{
James C. Winter ${ }^{1 凶}$, Gary L. Darmstadt ${ }^{2}$, Alexandria B. Boehm (iD) and Jennifer Davis ${ }^{1,3}$
}

Reliable access to water, sanitation, and hygiene (WASH) services is a critical component of child health and development. However, as piped water systems with taps conveniently close to households are rare in rural, sub-Saharan Africa, there is limited evidence of their impact. We conducted a quasi-experimental study in four rural villages of southern Zambia between April 2018 and May 2019 in which we measured the impact of installing on-premises piped water systems on fecal contamination of stored water and caregivers' hands. Gaining access to piped water was associated with a $0.5 \log _{10}$ reduction of $E$. coli concentration in drinking water $(p<0.05)$ but no changes in hand contamination. The piped water systems in this study reduced the median distance to a safe drinking water source by over $90 \%$, but we measured only small improvements in microbiological outcomes and no changes in the duration of self-reported, in-home water storage. These findings emphasize the need for future impact assessments of piped water systems to measure a comprehensive set of indicators directly linked to human well-being such as time savings.

npj Clean Water (2021)4:47; https://doi.org/10.1038/s41545-021-00138-x

\section{INTRODUCTION}

Reliable access to water, sanitation, and hygiene (WASH) services is a critical component of early childhood health and development ${ }^{1}$. There have been substantial gains in access to improved water sources over the past 20 years; however, progress in subSaharan Africa is much more limited than in other regions ${ }^{2}$. Children living in low- and middle-income countries bear a substantial burden of diseases attributable to inadequate WASH services ${ }^{1}$. Diarrheal disease alone was responsible for nearly 300,000 deaths of children under 5 years of age in 2016, approximately $50 \%$ of which occurred in sub-Saharan Africa ${ }^{1}$.

There are many pathways by which children can be exposed to fecal contamination, including their own hands, their caregivers' hands, and stored drinking water ${ }^{3-9}$. Recent research has measured the impacts of increasing access to chlorine-based water disinfection, improved pit latrines, tools for child feces management, and portable handwashing stations on child health $^{10-12}$. However, these household-level interventions have not resulted in significant reductions in under-5 child linear growth faltering $^{10}$ or in diarrheal prevalence ${ }^{11,12}$. The limited impact observed in these studies has led some to suggest that future investments must focus on transformative solutions that are "radically more effective in reducing fecal contamination"13,14.

Piped water systems with yard or house taps are designed to distribute relatively large quantities of water to a conveniently close location. The transition to these systems is hypothesized to improve access to safe drinking water and increase handwashing frequency and thoroughness ${ }^{15,16}$. However, piped water systems also represent a much higher per-capita cost investment in household water supply. Such systems are rare in rural areas of low-income countries, especially in sub-Saharan Africa. Currently, just $18 \%$ of rural households in sub-Saharan Africa have access to piped water and coverage has expanded by only five percentage points since $2000^{2}$.

As piped, on-premises water systems are not common in lowand middle-income countries, they are largely absent from literature measuring their impact on hand hygiene, water quality, or health. For example, studies that measured indicators of hand hygiene have not included households relying on piped water sources, which may mask a relationship between water source, water access, and hand hygiene ${ }^{3,17}$. A recent systematic review and meta-analysis conducted by Wolf and others ${ }^{18}$ included 70 studies on shared community sources, compared to nine studies on piped, on-premises service. This stands in contrast to higher-income countries, where the relationships between treated piped water and health have been thoroughly investigated ${ }^{19,20}$.

However, similar to other interventions aimed at interrupting household fecal exposure pathways ${ }^{11,12}$, studies on the impacts of transitioning to piped water have not shown conclusive reductions in diarrheal disease prevalence. For example, a review by Overbo et al. ${ }^{21}$ found statistically significant associations between on-plot piped water provision and reductions in under- 5 diarrheal disease in five of the ten rigorous studies, with the balance reporting null findings. Further clarity is needed on pathways whereby piped water can significantly reduce exposure to fecal pathogens and/or improve child health.

In this study, we first hypothesize the mechanisms by which transitioning from unimproved, off-plot water supply to onpremises piped water affects fecal exposure and child health. Then, we use empirical data from rural Zambia to understand the effects of that transition on a combination of microbiological and caregiver-reported child health outcomes.

\section{CONCEPTUAL MODEL}

Our conceptual model was developed through a literature review and pilot study conducted in January 2018 in Zambia (Fig. 1). The model elaborates the hypothesized effects of the interventiongaining access to shared or private piped water taps-on fecal contamination on hands and in water. In our study sites, the piped water systems accessed deep groundwater sources free of fecal contamination. We hypothesize that, by bringing piped water

\footnotetext{
'Department of Civil and Environmental Engineering, Stanford University, Stanford, CA, USA. ${ }^{2}$ Department of Pediatrics, Stanford University School of Medicine, Stanford, CA, USA.

${ }^{3}$ Woods Institute for the Environment, Stanford University, Stanford, CA, USA. ${ }^{凶}$ email: jcwinter@alumni.stanford.edu
} 


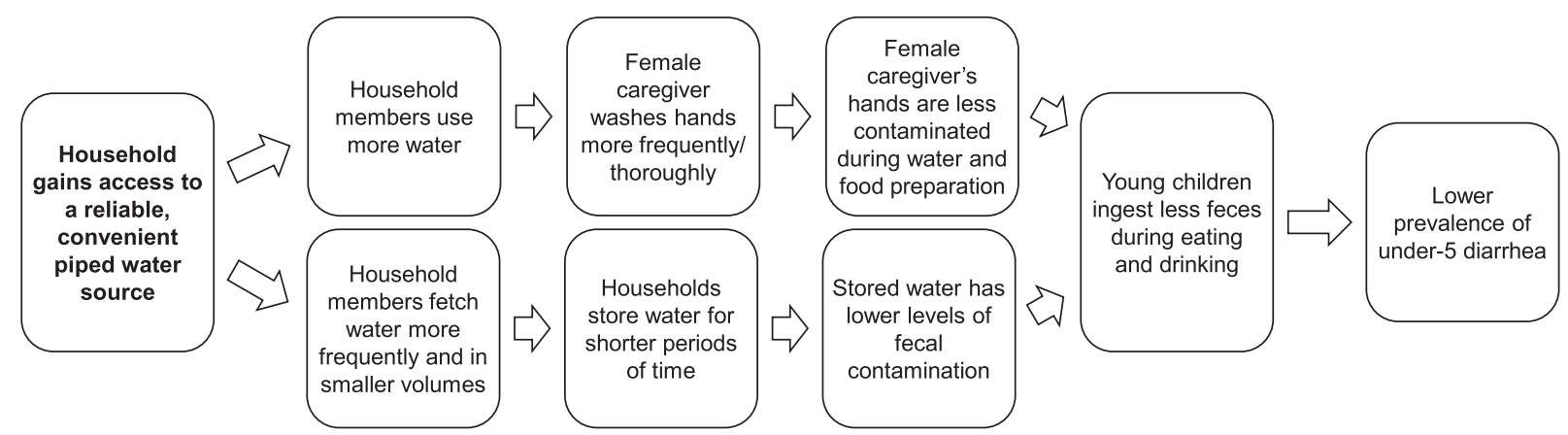

Fig. 1 Conceptual model. Hypothesized relationship between piped water access and key study outcomes.

closer to the home, households will use more water overall and will allocate an increased volume toward hygiene behaviors such as handwashing ${ }^{15,16}$. More frequent handwashing is expected to result in less fecal contamination on the hands of caregivers, who are typically female in this context. By cleaning their hands more frequently and/or thoroughly, caregivers can reduce the chance of contaminating the food and water they prepare for their children, thereby reducing fecal pathogen exposures for their children ${ }^{22,23}$. Cleaning young children's hands more frequently can also reduce the chance of fecal ingestion during hand mouthing ${ }^{8,24}$.

We also hypothesize that bringing the water supply much closer to the home will result in households fetching water more frequently, but in smaller volumes per trip. If households are only fetching water as needed, we hypothesize that this would result in less reliance on in-home water storage. Previous systematic reviews and meta-analyses find that storing water without a lid or on the ground is associated with observed contamination of water after collection from the source ${ }^{25,26}$. Reducing the duration of water storage in the home would be expected to result in lower contamination of stored water and the consumption of water with a lower concentration of fecal indicator bacteria, which has been associated with reduced prevalence of diarrhea ${ }^{27}$.

\section{RESULTS}

\section{Baseline characteristics}

This study was conducted in four villages in southern Zambia in 2018-19. Two treatment villages were provided with a mechanized piped water network that pumped untreated deep groundwater to 20-25 taps with underground piping and a submersible pump. After installation, each tap was used by 1 to 4 households [mean $=2.9, \mathrm{SD}=1.2$ ]. A map of the study area is included in the Supplemental Information (SI) (Supplementary Fig. 2).

None of the socioeconomic or demographic characteristics measured were significantly different between the two treatment villages and the two comparison villages at baseline (Table 1). A higher proportion of households in comparison villages had an improved primary drinking water source (36\% vs. $7 \%, p<0.001)$, consistent with the emphasis the implementing partner, World Vision, places on prioritizing the neediest communities for their program. This difference was driven by treatment households at baseline relying almost exclusively on unimproved wells as their primary water source, whereas comparison households had some access to boreholes with handpumps. Unimproved wells were categorized according to the Joint Monitoring Program definitions and refer to dug wells without lining, apron, and/or cover ${ }^{28}$. In addition, prior to baseline data collection, treatment households were instructed by World Vision to construct a handwashing station and a shared or private latrine as a precondition of the piped water system being completed. This resulted in baseline differences between the treatment and comparison groups in reported use of a shared or private latrine to defecate $(82 \%$ vs.
$48 \%, p<0.001)$ and the observed presence of a handwashing station $(57 \%$ vs. $9 \%, p<0.001)$.

Microbiological quality of water sources. Escherichia coli (E. coli) concentrations in all source water samples from shared or private taps $(N=16)$ were below the limit of detection of 1 Most Probable Number (MPN)/100 mL $\left(-0.3 \quad \log _{10} \mathrm{MPN} / 100 \mathrm{~mL}\right)$ (Fig. 2). In samples taken over three time periods, we measured a median of $2.0 \log _{10}$ MPN E. coli/100 mL in unimproved wells (interquartile range $[\mathrm{IQR}]=1.4$ to $2.4 \log _{10} \mathrm{MPN} / 100 \mathrm{~mL}, N=78$ ) and a median of $-0.3 \log _{10} \mathrm{MPN} / 100 \mathrm{~mL}$ (IQR $=-0.3$ to $-0.3 \log _{10} \mathrm{MPN} / 100 \mathrm{~mL}$, $N=17$ ) at boreholes with handpumps ${ }^{29}$. Overall, $99 \%$ of samples taken from unimproved wells, $18 \%$ of samples taken from boreholes with handpumps, and $0 \%$ of samples taken from shared or private taps had detectable $E$. coli. Additional descriptive statistics can be found in the SI (Supplementary Table 4).

Distance to primary source. At baseline, households obtained water from unimproved wells and boreholes with handpumps. The median distance between a household's dwelling and its primary water source was $286 \mathrm{~m}(\mathrm{IQR}=109-471 \mathrm{~m})$. After the installation of shared and private taps, households in the treatment group lived a median of $13 \mathrm{~m}(\mathrm{IQR}=8-27 \mathrm{~m})$ away from their primary drinking water source. There were no measured changes in water source access in comparison villages and, as a result, their distance to their primary water source did not change between study periods. All distances were measured using Global Positioning System devices.

Handwashing and hand contamination. We found only marginal differences in self-reported handwashing frequency, measured as self-reported handwashing events in the day prior to the interview, between treatment, and comparison households at endline [estimate $=+0.6$ handwashing events that day, $95 \%$ confidence interval $(\mathrm{Cl})=(-0.0$ to 1.2$), p=0.07$ ] (full model reported in SI, Supplementary Table 2). Similarly, we measured no significant change in MPN E. coli per two hands associated with gaining piped water access when using microbiological analysis of hand-rinse samples (estimate $=-0.3 \log _{10}$ MPN per two hands, $95 \% \mathrm{Cl}(-0.9$ to 0.3$), p=0.4$ ) (Supplementary Table 2).

In-home drinking water quality and storage. Receiving piped water was associated with a $71 \%$ (307 observations of 148 households) decrease in $E$. coli concentration in stored water (estimate $=-0.5 \log _{10}$ MPN, $95 \% \mathrm{Cl}:(-1.0$ to 0.0$), p=0.03$, Table 2, full model reported in SI, Supplementary Table 3). In 63\% ( $N=$ 33) of treatment households, however, there continued to be $E$. coli contamination above the limit of detection. Descriptive statistics on concentration of $E$. coli by treatment group and phase can be found in the SI, Supplementary Table 5 .

In household surveys, both treatment and comparison households reported fetching their drinking water on the day of interview more frequently at endline than at baseline, but the 
Table 1. Baseline socioeconomic and WASH characteristics of respondents, by study group.

\section{Characteristic}

Number of respondents

Mean number of household members (SD)

Mean number of children under 5 years (SD)

Mean respondent's years of formal education (SD)

Household's primary drinking water source is improved

Mean number of water sources used for all purposes by the household (SD)

Percentage reporting being "somewhat" or "very" satisfied with accessibility of primary water source

Percentage reporting being "somewhat" or "very" satisfied with primary water source overall

Median self-reported per-capita monthly expenditure in \$US (interquartile range)

Mean land ownership (hectares, SD)

Percent storing water with a lid

Percent storing water off the ground

Percent reporting fetching stored water on day of interview

Percent reporting that adults use a shared or private latrine to defecate

Percent reporting that they had a dedicated place to wash their hands

Percent reporting owning chickens

Percent reporting owning cattle

Mean household's Demographic and Health Survey Wealth Index value (SD)

Comparison households Treatment households

\begin{tabular}{ll}
109 & 45 \\
$5.8(2.8)$ & $6.6(3.4)$ \\
$1.7(1.1)$ & $1.6(0.8)$ \\
$7.4(2.7)$ & $7.5(3.2)$ \\
$36 \%^{*}$ & $7 \%$ \\
$1.2(0.4)$ & $1.3(0.5)$ \\
$51 \%$ & $47 \%$ \\
$48 \%$ & \\
$\$ 3.65(1.9-6.4)$ & $38 \%$ \\
$3.5(4.3)$ & $\$ 4.62(2.2-7.7)$ \\
$86 \%$ & $5.7(7.4)$ \\
$32 \%$ & $89 \%$ \\
$72 \%$ & $38 \%$ \\
$48 \%$ & $71 \%$ \\
$9 \%$ & $82 \% *$ \\
$82 \%$ & $57 \% *$ \\
$47 \%$ & $84 \%$ \\
$0.19(0.3)$ & $42 \%$ \\
\hline
\end{tabular}

Significance tests conducted using paired $t$-tests for differences in means, Wilcoxon rank-sum test for differences in medians, and $x^{2}$-tests for differences in binary responses.

${ }^{*} p<0.001$.

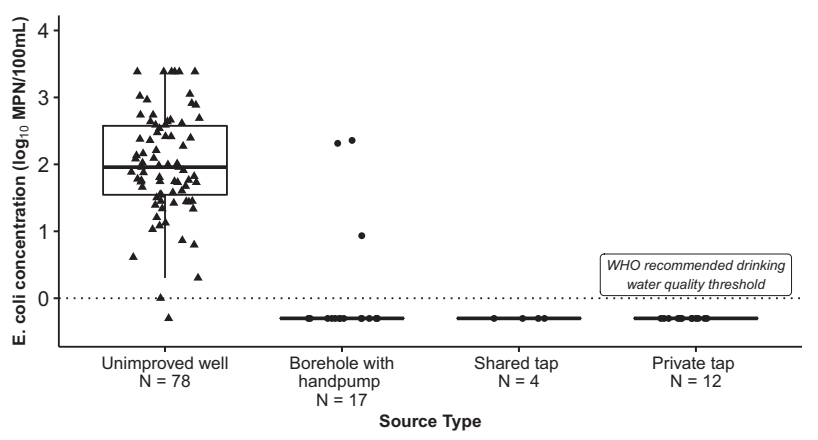

Fig. 2 Source water quality. Boxplot of $E$. coli concentration ( $\log _{10}$ MPN/100 mL) in source water samples by source type, combined across all study phases.

differences between treatment groups were not statistically significant $\left(x^{2}\right.$-test of association, two-sided, $x^{2}=0.2, p=0.6$ ) (Fig. 3). In addition, we found no significant associations between distance to primary source and duration of water storage. In other words, households who lived $<13 \mathrm{~m}$ (quintile 1 ) from their primary water source reported statistically identical water storage practices as households living more than $500 \mathrm{~m}$ (quintile 5) from their primary water source (additional details in SI, Supplementary Fig. 3).

Diarrheal disease prevalence. Among treatment households, there was no significant difference between baseline and endline in the 7-day prevalence of caregiver-reported diarrheal disease in children under 5 years ( $18 \%$ to $9 \%, p=0.24$, Fig. 4). However, in comparison households, there were large and significant increases in this indicator $(5 \%$ to $28 \%, p<0.001)$. Taken together, the provision of piped water was associated with reductions in the odds of caregivers reporting diarrheal disease in under- 5 children (odds ratio $=0.1,95 \% \mathrm{Cl}$ : $(0.0-0.7), p<0.05)$. This analysis was
Table 2. Estimated impact of receiving piped water on microbiological contamination of stored drinking water ( $\log _{10}$ Most Probable Number E. coli/100 mL) from multivariate linear mixed effects model.

\begin{tabular}{|c|c|}
\hline Predictors & $\begin{array}{l}\text { Change in E. coli concentration in household } \\
\left.\text { stored drinking water ( } \log _{10} \mathrm{MPN} / 100 \mathrm{~mL}\right) \\
\text { Estimate }(95 \%)\end{array}$ \\
\hline Intercept & $1.5^{*}(1.1$ to 1.9$)$ \\
\hline Received piped water & $-0.5^{* *}(-1.0$ to 0.0$)$ \\
\hline $\begin{array}{l}\text { Number of observations } \\
\text { (clusters) }\end{array}$ & 307 (148) \\
\hline Conditional $R^{2}$ & 0.23 \\
\hline
\end{tabular}

Reported type of latrine used by adults in the household, observed presence of a handwashing station at home, observed presence of soap at the handwashing station, self-reported water treatment, and household wealth quintile are included as control variables. Full model output is included in the SI, Table S3.

${ }^{*} p<0.001$.

${ }^{* *} 0.01 \leq p<0.05$

performed on the sub-sample of our population that reported having a child under the age of 5 years during the study period ( $N=79$ at baseline, $N=74$ at endline). Neither of the negative control health outcomes, toothaches or cuts and scrapes, changed significantly over time in either cohort.

\section{DISCUSSION}

Providing rural Zambian households with shared and private piped water taps at a conveniently close location was associated with small but statistically significant reductions in water contamination at the point of consumption. Receiving the 
Baseline

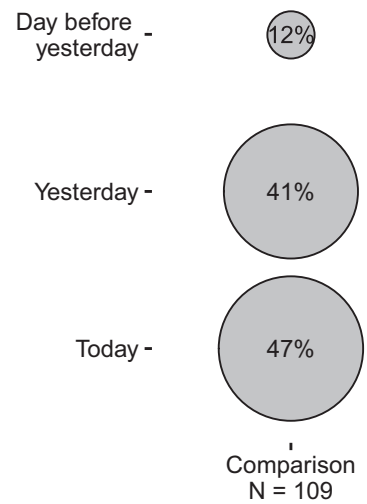

$9 \%$
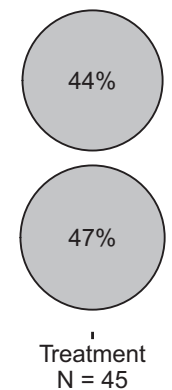

(7\%)

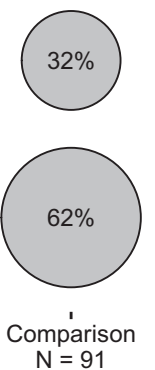

$5 \%$

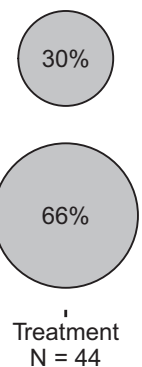

Fig. 3 Self-reported water storage behavior. Self-reported collection day of stored water in the home, by group and study phase, with area of circle representing relative proportion within each column.

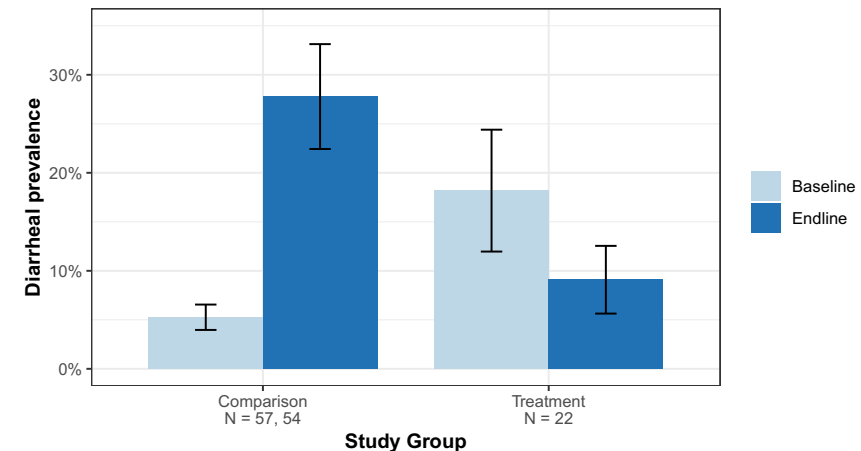

Fig. 4 Self-reported diarrheal prevalence. Seven-day prevalence of caregiver-reported clinical diarrhea in under-5 children, by study phase and group.

intervention was associated with no significant changes in selfreported handwashing frequency or microbiological indicators of hand contamination.

Receiving piped water was associated with a $71 \%\left(0.5 \log _{10}\right)$ reduction in the concentration of fecal indicator bacteria in stored drinking water (MPN/100 mL). The magnitude of these results are similar to another recent study on piped water systems in Zimbabwe ${ }^{7}$. However, there continued to be measurable $E$. coli contamination in 33 out of 52 (63\%) stored water samples in treatment households. These findings suggest that contamination occurred between collection from the source and consumption, even in households accessing their water from nearby piped water sources.

Post-supply contamination has been associated with extended household storage prior to consumption ${ }^{25,30}$. We hypothesized that households gaining access to piped water would store their water for less time prior to consuming it (Fig. 1). However, we found no evidence of differences in storage time between treatment and comparison households, nor any associations between storage time and distance to primary source (Fig. 3 and Supplementary Fig. 3). We speculate that these findings are due to community members' lack of trust in the continued functionality and sustainability of the water system. Intermittency of supply may be a key factor explaining why households continue to store water. If water supply can be exhausted or shut off unexpectedly, it is risky for a household to abandon water storage entirely. Therefore, even if a water tap is located close to home, previously adopted water storage behaviors may not change in the short term. In addition, although the piped water systems were functional throughout the survey period, there is ample evidence of frequent breakdowns of rural water supply infrastructure ${ }^{31-34}$. This could result in households continuing previous storage behaviors until they develop confidence in the system's long-term functionality. Given the rapid time between intervention and evaluation ( $<12$ months), respondents were unlikely to have developed that level of trust or to have changed entrenched water storage behaviors. It is possible however that longer-term evaluations of water storage behavior would find larger changes.

The existing literature on handwashing has suggested that improved access to water is a key barrier to increasing handwashing frequency ${ }^{15,16,35,36,37}$. In addition, availability of water could plausibly be linked to increased thoroughness or duration of handwashing. However, we found no change in either the self-reported number of handwashing events or the microbiological indicators of hand contamination ( $E$. coli $\log _{10}$ MPN per two hands). Previous research has suggested that self-reported handwashing frequency is an indicator that is susceptible to social desirability bias and may represent an inflated measure of handwashing frequency compared to observed or directly measured frequency ${ }^{38,39}$. Therefore, the lack of significant effect using this indicator reinforces our assessment that handwashing rates did not significantly increase. This finding aligns with evidence from high-income countries that finds that infrastructure interventions in isolation are insufficient to catalyze improved hand hygiene behaviors ${ }^{40}$. Therefore, additional community or household-level messaging is likely required to further encourage handwashing.

We measured significant increases in diarrheal prevalence in comparison villages and non-significant decreases in treatment villages. A difference-in-difference analysis showed a statistically significant reduction in caregiver-reported diarrhea in under-5year-old children. The secular increase in diarrheal prevalence in comparison villages was an unexpected finding that contributed importantly to the difference-in-difference result. Although it is possible that a protective effect of the piped water systems prevented the treatment villages from experiencing a similarly large increase in diarrheal prevalence over the study period, we believe that other factors may contribute to this finding. For example, it is possible that respondents provided answers to our questions about diarrheal prevalence, whether intentionally or not, to demonstrate need, show gratitude, or for other reasons ${ }^{41}$. This may have been especially prevalent in comparison villages, which did not receive any benefits during the study period. However, we saw no evidence of this behavior in measures of 
other health indicators, suggesting that if this bias occurred, it was isolated to reporting of diarrheal episodes.

In addition, we acknowledge that the assignment of treatment status in this study was non-random. Although comparison villages were matched based on a set of pre-specified covariates, there were significant differences in the proportion of households using a shared or private latrine and having access to a handwashing station at baseline. Although our models statistically controlled for these differences, the non-random assignment may have also resulted in imbalances in other, unmeasured confounders. Moreover, the number of episodes of diarrhea among our study population was small. Therefore, although we found a significant protective effect of piped water infrastructure for diarrheal disease, we believe these findings should be interpreted with caution until they are corroborated by subsequent studies.

Finally, our study focuses exclusively on the potential benefits of the piped water systems included in the sample. Cost data for installation, maintenance, and management were not made available to the researchers and represents a limitation of this work. Although some literature has provided life cycle cost estimates for rural piped water systems in low-income countries, the analyses were performed on systems orders of magnitude larger than those in this study ${ }^{42}$. Therefore, there remains a gap in the literature measuring the life cycle costs of small, rural piped water systems.

Recent large, randomized controlled experiments have found limited impacts of household WASH improvements on child health and linear growth ${ }^{10-12}$. As a result, there have been calls for additional investment in civil infrastructure, on-premises water

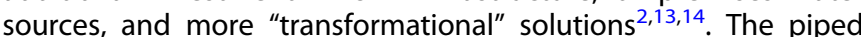
water systems in this study exemplify a transformational approach, providing on-premises piped water systems that delivered water free of fecal contamination and reduced the distance to the primary drinking water source by over $90 \%$. Despite this, we measured only marginal improvements in stored water quality and no changes in $E$. coli concentration on hands, handwashing frequency, or household water storage.

However, providing on-premises piped water is still a worthy goal that has been associated with large improvements in outcomes directly linked to human well-being. For example, similar interventions have been associated with improvements in time savings $s^{43}$, household income ${ }^{44,45}$, productive uses of water ${ }^{46}$, food security ${ }^{47}$, musculoskeletal injuries ${ }^{48,49}$, and psychosocial health ${ }^{50,51}$. We therefore propose that future research seeking to understand the potential impact of transformational WASH prioritizes a broad set of well-being measures in addition to further examining microbiological and, where possible, verified health indicators.

\section{METHODS}

\section{Study site, sample frame, and design}

This study was conducted in two neighboring districts of southern Zambia in 2018-19. In 2018, the international non-governmental organization World Vision, constructed 14 piped water systems in rural villages. The villages that received piped water networks were selected by local World Vision field offices based on comparatively high levels of perceived need. Treatment and comparison villages were matched based on their access to a health care facility and proximity to a primary school. In both treatment villages ( $\mathrm{T} 1$ and $\mathrm{T} 2$ ) and one comparison village (C1), all female household heads were asked to participate in the study. In the second comparison village (C2), a systematic sampling procedure was used to select two out of every three households due to its larger size. One household refused to participate at baseline. The study design implemented was a nonrandomized, quasi-experimental design. A participant flow chart and map of the study site are included in the SI (Supplementary Figs. 1 and 2). We report our methods and results in accordance with Transparent Reporting of Evaluations with Nonrandomized Designs guidelines in the SI (Supplementary Table 1$)^{52}$.

\section{Intervention}

Treatment villages were provided with a mechanized piped water network that included underground polyvinyl chloride piping and a submersible pump. In both villages, between 20 and 25 taps were installed, with a mix of private yard taps and taps shared by two to five households. Water was delivered for $\sim 8-16 \mathrm{~h}$ per day. The boreholes and piped systems in the study villages all used deep groundwater sources.

\section{Data collection}

Data collection occurred in May 2018 (baseline), September 2018 (midline), and June 2019 (endline). Baseline and endline data collection occurred at the beginning of the dry season, whereas midline data collection occurred at the end of the dry season. Interviews were conducted in the participants' yards and covered topics including water fetching and handling practices, sanitation, and hygiene behaviors. In total, 434 household surveys were conducted over the three study periods. Interviews were conducted in Tonga, the local language of the study sites by Zambian research assistants who had completed 2 weeks of intensive training and pretesting, and were fluent in Tonga and English. All surveys were written in English, translated into Tonga by a third-party translator, and back-translated into English by the research assistants. All data were collected using tablet computers or cell phones using SurveyCTO software (Dobility, Cambridge, MA).

The same households were visited for an interview by the enumeration team during each data collection period. At baseline, 154 households were interviewed. At midline and endline, repeat surveys were completed with $90 \%(N=138)$ and $81 \%(N=125)$ of the households, respectively. Three quarters $(N=114)$ of households were interviewed at all three time periods. Up to three interview attempts were made to each household, to maximize retention across study phases.

The primary study outcomes are the levels of E. coli on respondents' hands and in household stored drinking water. The secondary outcomes are the level of $E$. coli in water collected directly from the source, the selfreported frequency of handwashing with soap by the interviewee, selfreported water storage duration in the home, and caregiver-reported 7day diarrheal prevalence for children under 5 years of age.

To measure hand contamination, we collected hand-rinse samples during each data collection period from a subset of households that also provided stored water samples. Due to limitations in the field laboratory capacity, it was not possible to collect hand-rinse samples from the same households at each time period. Therefore, the 175 total samples were taken from 109 unique households over the three periods of data collection. Samples were collected by asking respondents to sequentially submerge their hands into a sterile Whirl-Pak bag containing $350 \mathrm{~mL}$ of distilled water, following the procedure described by ${ }^{37}$. We also asked respondents how many times they washed their hands during the previous day, in total and with soap.

To measure $E$. coli contamination in stored water, we collected stored water samples during all three periods of data collection from a subset of respondents ( $N=267$ samples from 148 unique households). Respondents were asked to decant $\sim 300 \mathrm{~mL}$ of water from the container they were currently using (or would use next) in the way they would normally serve themselves, into a sterile Whirl-Pak bag. Samples were kept on ice and transported to a field laboratory where they were analyzed within $6 \mathrm{~h}$ of collection. Due to limitations in transport from the rural communities to the field laboratory, if the interview began before $1100 \mathrm{~h}$, water and hand samples were not taken, because the duration between sampling and processing was expected to be more than $6 \mathrm{~h}$.

To measure the duration of in-home water storage, respondents were asked: "If you were to take a drink of water right now, where would you draw it from?". If they referenced a storage vessel, they were asked, "When was this water fetched?", as well as the source from which it was fetched. Responses were recorded as that afternoon, that morning, yesterday, the day before yesterday, or earlier than that.

All source water, stored water, and hand-rinse samples were analyzed for E. coli using the IDEXX Colilert and Quanti-tray 2000 process (Westbrook, ME). To measure $E$. coli contamination in village water sources, we identified all water sources that respondents used for drinking during household surveys ( $N=111$ over three data collection periods). An enumerator collected $\sim 300 \mathrm{~mL}$ of water from each water source during each data collection period. Samples were collected in sterile Whirl-Pak bags (Nasco, Fort Atkinson, Wl), kept on ice, and transported to a field laboratory, where analysis was performed within $6 \mathrm{~h}$ of sample collection. 
For hand-rinse samples, after agitation, $100 \mathrm{ml}$ of water was transferred from the $350 \mathrm{~mL}$ sample bag for analysis. The limits of detection were 3.5 MPN/2 hands and 8468 MPN/2 hands. Water samples with concentrations below the limit of detection were assigned a value of $0.5 \mathrm{MPN}$ and samples with concentrations above the upper limit were assigned a concentration of $2420 \mathrm{MPN} / 100 \mathrm{~mL}$. Hand samples with concentrations below the limit of detection were assigned a value of 2 MPN/2 hands and samples with concentrations above the upper limit were assigned a concentration of 8469 MPN/2 hands $^{53}$.

One field blank, one laboratory blank, and one randomly selected laboratory replicate (two aliquots from the same sample bag) per day were conducted for quality control. Field blanks were sample bags filled with distilled water that were carried in the refrigerated cooler to the study village, opened and closed outside the project vehicle, and returned to the refrigerated cooler. Laboratory blanks were $100 \mathrm{ml}$ aliquots of the laboratory distilled water. All blanks were tested for $E$. coli. Based on the sample volume processed, the limits of detection were $1 \mathrm{MPN} / 100 \mathrm{ml}$ and $2419 \mathrm{MPN} / 100 \mathrm{~mL}$. No E. coli was detected in any of the field or laboratory blank samples during this study.

We measured diarrheal prevalence in children under the age of 5 years through caregiver surveys. Caregivers with weaned children under 5 years were asked whether their child had experienced specific health symptoms in the past 7 days. We used the World Health Organization case definition of diarrhea (three or more loose or watery stools in the past $24 \mathrm{~h}$ ) as our indicator of diarrheal disease. Caregivers were also asked about other health symptoms for the child, including fever, vomiting, and cough, as well as two negative controls: toothaches, and cuts and scrapes ${ }^{54}$.

\section{Data analysis}

Data were analyzed using $\mathrm{R}$ version 3.6.1 (R Foundation, Vienna, Austria). We calculated differences in $\log _{10}$-transformed $E$. coli concentrations for hand rinses and stored water using linear mixed effects models with random intercepts to account for clustering at the household level using the Ime4 package ${ }^{55,56}$. Both models controlled for selection into the treatment group, the reported type of latrine, if any, used by the adults for defecation, the observed presence of a dedicated handwashing station used by the household, and whether soap was observed at the handwashing station during the interview. These covariates were prespecified based on previous studies reporting on the potential for hands to contaminate water during extraction events ${ }^{17,30,57}$. Differences in caregiver-reported, under-5 diarrheal prevalence and water storage duration were measured using generalized linear mixed effects models with the same control variables, random effects, and analysis packages. The model estimating differences in stored water quality used an additional control variable for whether the households reported treating their drinking water "somewhat frequently" or "often." We used the DHARMa package in R (version 0.4.1) to validate that all assumptions for linear and generalized linear mixed effects models were met $^{58}$. All models used data from all three data collection periods.

All models include a composite wealth score as a final control variable. Information on how the wealth score was calculated is included in the SI.

We defined exposure to the intervention as a household reporting using a shared or private tap connected to the village's piped water network as their primary water source. Fourteen households lived in a treatment village but were not served by the new system and were thus excluded from the sample. All analyses reported are thus "treatment on the treated," where only those using piped water as their primary water source are considered in the treatment group ${ }^{59}$.

\section{Ethics statement}

Ethics approval was obtained from the Institutional Review Board of Stanford University (Protocol 44976) and the Biomedical Research Ethics Committee of the University of Zambia (Ref 001-03-18). Researchers met with community leaders in the four villages to describe the research protocols prior to the commencement of study activities. Prior to participation, all respondents voluntarily provided informed oral consent to enumerators who were fluent in the local language. All study participants were at least 18 years of age.

\section{DATA AVAILABILITY}

The data that support the findings of this study are not openly available due to sensitivity around the depth of household-level survey data collected. However, all anonymized data sets generated during and/or analyzed during the current study, as well as the accompanying code, are available from the corresponding author on reasonable request.

Received: 14 May 2021; Accepted: 1 October 2021;

Published online: 22 October 2021

\section{REFERENCES}

1. Prüss-Ustün, A. et al. Burden of disease from inadequate water, sanitation and hygiene for selected adverse health outcomes: An updated analysis with a focus on low- and middle-income countries. Int. J. Hyg. Environ. Health 222, 765-777 (2019).

2. WHO/UNICEF Joint Monitoring Program. Progress on Household Drinking Water, Sanitation and Hygiene 2000-2017. Special Focus on Inequalities. WHO/UNICEF Joint Monitoring Program, 2019).

3. Ercumen, A. et al. Effects of single and combined water, sanitation and handwashing interventions on fecal contamination in the domestic environment: a Cluster-Randomized Controlled Trial in Rural Bangladesh. Environ. Sci. Technol. 52, 12078-12088 (2018).

4. Ercumen, A. et al. Do sanitation improvements reduce fecal contamination of water, hands, food, soil, and flies? Evidence from a Cluster-Randomized Controlled Trial in Rural Bangladesh. Environ. Sci. Technol. 52, 12089-12097 (2018).

5. Pickering, A. J. et al. Fecal indicator bacteria along multiple environmental transmission pathways (water, hands, food, soil, flies) and subsequent child diarrhea in rural Bangladesh. Environ. Sci. Technol. 52, 7928-7936 (2018).

6. Mattioli, M., Davis, J., Mrisho, M. \& Boehm, A. B. Quantification of human norovirus Gll on hands of mothers with children under the age of five years in Bagamoyo, Tanzania. Am. J. Trop. Med. Hyg. 93, 478-484 (2015).

7. Navab-Daneshmand, T. et al. Escherichia coli contamination across multiple environmental compartments (soil, hands, drinking water, and handwashing water) in urban Harare: Correlations and risk factors. Am. J. Trop. Med. Hyg. 98, 803-813 (2018).

8. Kwong, L. H. et al. Ingestion of Fecal Bacteria along Multiple Pathways by Young Children in Rural Bangladesh Participating in a Cluster-Randomized Trial of Water, Sanitation, and Hygiene Interventions (WASH Benefits), https://doi.org/10.1021/acs. est.0c02606 (2020).

9. Holcomb, D. A. et al. Human fecal contamination of water, soil, and surfaces in households sharing poor-quality sanitation facilities in Maputo, Mozambique. Int. J. Hyg. Environ. Health 226, 113496 (2020).

10. Luby, S. P. et al. Effects of water quality, sanitation, handwashing, and nutritional interventions on diarrhoea and child growth in rural Bangladesh: a cluster randomised controlled trial. Lancet Glob. Heal. 6, e302-e315 (2018).

11. Null, C. et al. Effects of water quality, sanitation, handwashing, and nutritional interventions on diarrhoea and child growth in rural Kenya: a cluster-randomised controlled trial. Lancet Glob. Heal. 6, e316-e329 (2018).

12. Humphrey, J. H. et al. Independent and combined effects of improved water, sanitation, and hygiene, and improved complementary feeding, on child stunting and anaemia in rural Zimbabwe: a cluster-randomised trial. Lancet Glob. Heal. 7, e132-e147 (2019).

13. Pickering, A. J. et al. The WASH Benefits and SHINE trials: interpretation of WASH intervention effects on linear growth and diarrhoea. Lancet Glob. Heal. 7, e1139-e1146 (2019).

14. Cumming, O. et al. The implications of three major new trials for the effect of water, sanitation and hygiene on childhood diarrhea and stunting: a consensus statement. BMC Med. 17, 1-9 (2019).

15. Oswald, W. E. et al. Provision of private, piped water and sewerage connections and directly observed handwashing of mothers in a peri-urban community of Lima, Peru. Trop. Med. Int. Heal. 19, 388-397 (2014).

16. Stelmach, R. D. \& Clasen, T. Household water quantity and health: a systematic review. Int. J. Environ. Res. Public Health 12, 5954-5974 (2015).

17. Pickering, A. J. et al. Hands, water, and health: fecal contamination in Tanzanian communities with improved, non-networked water supplies. Environ. Sci. Technol. 44, 3267-3272 (2010).

18. Wolf, J. et al. Impact of drinking water, sanitation and handwashing with soap on childhood diarrhoeal disease: updated meta-analysis and meta-regression. Trop. Med. Int. Heal. 23, 508-525, https://doi.org/10.1111/tmi.13051 (2018)

19. Alsan, M. \& Goldin, C. Watersheds in child mortality: the role of effective water and sewerage infrastructure, 1880 - 1920 Marcella Alsan Claudia Goldin. J. Polit. Econ. 127, 586-638 (2019).

20. Cutler, D. \& Miller, G. The role of public health improvements in health advances: the twentieth-century United States. Demography 42, 1-22 (2005).

21. Overbo, A., Williams, A. R., Evans, B., Hunter, P. R. \& Bartram, J. On-plot drinking water supplies and health: a systematic review. Int. J. Hyg. Environ. Health 219, 317-330 (2016). 
22. Mattioli, M., Davis, J. \& Boehm, A. B. Hand-to-mouth contacts result in greater ingestion of feces than dietary water consumption in Tanzania: a quantitative fecal exposure assessment model. Environ. Sci. Technol. 49, 1912-1920 (2015).

23. Pickering, A. J., Julian, T. R., Mamuya, S., Boehm, A. B. \& Davis, J. Bacterial hand contamination among Tanzanian mothers varies temporally and following household activities. Trop. Med. Int. Heal. 16, 233-239 (2011).

24. Kwong, L. H. et al. Hand- and object-mouthing of rural bangladeshi children 3-18 months old. Int. J. Environ. Res. Public Health 13, 563 (2016).

25. Wright, J., Gundry, S. \& Conroy, R. Household drinking water in developing countries: a systematic review of microbiological contamination between source and point-of-use. Trop. Med. Int. Heal. 9, 106-117 (2004).

26. Shields, K. F., Bain, R. E. S., Cronk, R., Wright, J. A. \& Bartram, J. Association of supply type with fecal contamination of source water and household stored drinking water in developing countries: a bivariate meta-analysis. Environ. Health Perspect. 123, 1222-1231 (2015).

27. Luby, S. P. et al. Microbiological contamination of drinking water associated with subsequent child diarrhea. Am. J. Trop. Med. Hyg. 93, 904-911 (2015).

28. WHO/UNICEF. Core Questions on Drinking-Water and Sanitation for Household Surveys (WHO/UNICEF, 2018).

29. World Health Organization. Guidelines for Drinking-water Quality (World Health Organization, 2017).

30. Harris, A. R., Boehm, A. B. \& Davis, J. Mechanisms of post-supply contamination of drinking water in Bagamoyo, Tanzania. J. Water Health 11, 543-554 (2013).

31. Foster, T. Predictors of sustainability for community-managed handpumps in sub-saharan Africa: evidence from Liberia, Sierra Leone, and Uganda. Environ. Sci. Technol. 47, 12037-12046 (2013).

32. Marks, S. J. \& Davis, J. Does user participation lead to sense of ownership for rural water systems? Evidence from Kenya. World Dev. 40, 1569-1576 (2012).

33. Whittington, D. et al. How well is the demand-driven, community management model for rural water supply systems doing? Evidence from Bolivia, Peru and Ghana. Water Policy 11, 696-718 (2009).

34. Dhoba, L. Going to scale with rural water supply: a reflection on experiences from sustaining community managed piped water schemes in rural Zimbabwe. J. Water Sanit. Hyg. Dev. 527-538, https://doi.org/10.2166/washdev.2020.081 (2020).

35. Coombes, Y. \& Devine, J. Introducing FOAM: A Framework to Analyze Handwashing Behaviors to Design Handwashing Programs. Water and Sanitation Program Working Paper (World Bank, 2010).

36. Dreibelbis, R. et al. The integrated behavioural model for water, sanitation, and hygiene: a systematic review of behavioural models and a framework for designing and evaluating behaviour change interventions in infrastructurerestricted settings. BMC Public Health 13, 1015 (2013).

37. Pickering, A. J., Boehm, A. B., Mwanjali, M. \& Davis, J. Efficacy of waterless hand hygiene compared with handwashing with soap: a field study in Dar es Salaam, Tanzania. Am. J. Trop. Med. Hyg. 82, 270-278, https://doi.org/10.1111/tmi.13051 (2010).

38. Biran, A. et al. Comparing the performance of indicators of hand-washing practices in rural Indian households. Trop. Med. Int. Heal. 13, 278-285 (2008).

39. Ram, P. K. et al. Is structured observation a valid technique to measure handwashing behavior? Use of acceleration sensors embedded in soap to assess reactivity to structured observation. Am. J. Trop. Med. Hyg. 83, 1070-1076 (2010).

40. Gould, D. J., Moralejo, D., Drey, N., Chudleigh, J. H. \& Taljaard, M. Interventions to improve hand hygiene compliance in patient care. Cochrane Database Syst. Rev. https://doi.org/10.1002/14651858.CD005186.pub4 (2017).

41. Zwane, A. P. et al. Being surveyed can change later behavior and related parameter estimates. Proc. Natl Acad. Sci. USA 108, 1821-1826 (2011).

42. Nyarko, K. B., Dwumfour-Asare, B., Appiah-Effah, E. \& Moriarty, P. Cost of delivering water services in rural areas and small towns in Ghana. In: IRC Symposium 2010: Pumps, Pipes and Promises 172-191 (IRC WASH, 2010).

43. Winter, J. C., Darmstadt, G. L. \& Davis, J. The role of piped water supplies in advancing health, economic development, and gender equality in rural communities. Soc. Sci. Med 270, 113599 (2021).

44. Renwick, M. et al. Multiple Use Water Services for the Poor: Assessing the State of Knowledge (Winrock International, 2007).

45. Van Houweling, E., Hall, R. P., Diop, A. S., Davis, J. \& Seiss, M. The role of productive water use in women's livelihoods: evidence from rural Senegal. Water Altern. 5, 658-677 (2012).

46. Hall, R. P., Vance, E. A. \& van Houweling, E. The productive use of rural piped water in Senegal. Water Altern. 7, 480-498 (2014).

47. Brewis, A. et al. Household water insecurity is strongly associated with food insecurity: evidence from 27 sites in low- and middle-income countries. Am. J. Hum. Biol. 32, 1-13 (2020).

48. Geere, J. et al. Carrying water may be a major contributor to disability from musculoskeletal disorders in low income countries: a cross-sectional survey in South Africa, Ghana and Vietnam. J. Glob. Health 8, 1-14 (2018).

49. Geere, J. L., Hunter, P. R. \& Jagals, P. Domestic water carrying and its implications for health: a review and mixed methods pilot study in Limpopo Province. South Africa. Environ. Heal. 9, 52 (2010).
50. Bisung, E. \& Elliott, S. J. Psychosocial impacts of the lack of access to water and sanitation in low- and middle-income countries: a scoping review. J. Water Health 15, 17-30 (2017).

51. Devoto, F., Duflo, E., Dupas, P., Parienté, W. \& Pons, V. Happiness on tap: piped water adoption in urban Morocco. Am. Econ. J. Econ. Policy 4, 68-99 (2012).

52. Des Jarlais, D. C., Lyles, C. \& Crepaz, N., TREND Group. Improving the reporting quality of nonrandomized evaluations of behavioral and public health interventions: The TREND Statement. Am. J. Public Health 94, 361-366 (2004).

53. Eaton, A. D., Clesceri, L. S. \& Greenberg, A. E. Standard Methods for the Examination of Water and Wastewater (American Public Health Association (APHA), 2005).

54. Arnold, B. F., Ercumen, A., Benjamin-Chung, J. \& Colford, J. M. Brief report negative controls to detect selection bias and measurement bias in epidemiologic studies. Epidemiology 27, 637-641 (2016).

55. Winter, B. Linear models and linear mixed effects models in $\mathrm{R}$ with linguistic applications. Preprint at, https://arXiv.org/abs/1308.5499 (2013).

56. McCulloch, C. E., Searle, S. R. \& Neuhaus, J. M. Generalized linear mixed models. Encycl. Biostat. 1-27, https://doi.org/10.1002/0470011815.b2a10021 (2005).

57. Trevett, A. F., Carter, R. C. \& Tyrrel, S. F. Mechanisms leading to post-supply water quality deterioration in rural Honduran communities. Int. J. Hyg. Environ. Health 208, 153-161 (2005).

58. Hartig, F. DHARMa: Residual Diagnostics for Hierarchical (Multi-Level/Mixed) Regression Models. $R$ package version 0.4.4. http://florianhartig.github.io/ DHARMa/ (2021).

59. Gupta, S. K. Intention-to-treat concept: a review. Perspect. Clin. Res. 2, 109-112 (2011).

\section{ACKNOWLEDGEMENTS}

Graduate funding for J.C.W. was provided by Stanford University Department of Civil \& Environmental Engineering, the Stanford Graduate Fellowship, and the U.S Fulbright Research Program. Additional funding for this study was provided by the Stanford King Center on Global Development and the Stanford Institute for Innovation in Developing Economies. Formative research was supported by the Stanford Office for International Affairs and the Stanford Global Engineering Program. We extend our gratitude to the households that agreed to participate in this study. We also recognize the innumerable contributions of our enumerator team to the project: Angel Mutale, Chookwa Lubombo, Cholwe Mweene, Felistas Chuunga, Harriet Ng'ombe, Orety Handiindo, Puumba Muchindu, and Saviour Sikalumbi. We thank World Vision staff, especially Maybin Ng'ambi, Emmanuel Nyundu, John Hasse, and Mark Kelly, for their enthusiastic collaboration and their assistance with research logistics in Zambia.

\section{AUTHOR CONTRIBUTIONS}

All authors contributed to conceptualization. J.C.W., G.L.D. and J.D. contributed to the design of survey instruments. J.C.W., A.B.B. and J.D. contributed to laboratory methods development. J.C.W. drafted manuscript text, conducted fieldwork, and conducted data analysis. J.D., A.B.B. and G.L.D. provided supervision. J.D. and G.L.D. provided funding. All authors contributed to manuscript review and editing.

\section{COMPETING INTERESTS}

World Vision funded the implementation of the piped water program described in this study. Prior to, and following the time frame of this project, Stanford University received a separate grant from World Vision for unrelated projects in which three of the authors (J.C.W., G.L.D. and J.D.) were involved. The authors declare no other competing interests.

\section{ADDITIONAL INFORMATION}

Supplementary information The online version contains supplementary material available at https://doi.org/10.1038/s41545-021-00138-x.

Correspondence and requests for materials should be addressed to James $C$. Winter.

Reprints and permission information is available at http://www.nature.com/ reprints

Publisher's note Springer Nature remains neutral with regard to jurisdictional claims in published maps and institutional affiliations. 
Access This article is licensed under a Creativ adaptation, distribution and reproduction in any medium or format, as long as you give appropriate credit to the original author(s) and the source, provide a link to the Creative Commons license, and indicate if changes were made. The images or other third party material in this article are included in the article's Creative Commons license, unless indicated otherwise in a credit line to the material. If material is not included in the article's Creative Commons license and your intended use is not permitted by statutory regulation or exceeds the permitted use, you will need to obtain permission directly from the copyright holder. To view a copy of this license, visit http://creativecommons. org/licenses/by/4.0/.

(c) The Author(s) 2021 